\title{
System is forcing low income patients to avoid dentists
}

Low income patients appear to be avoiding trips to the dentist due to the way the current system has created a 'hostile environment' for them in dental practices, according to the BDA.

The union has warned that these patients are keeping away from dentists and suffering the consequences of missed dental treatment because of the way the system is geared to keep costs down.

Official figures ${ }^{1}$ from NHS Digital released on 30 August 2018 showed a fall of almost

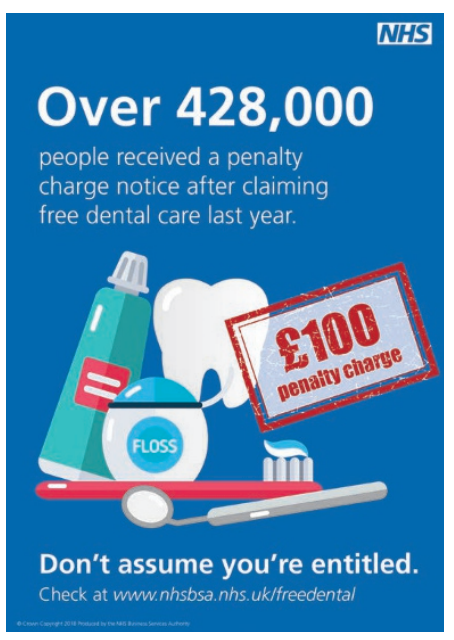
two million treatments delivered to patients exempt from NHS charges since 2013-14 (a fall of 23\% in four years) - 8,818,170 free courses of treatment were provided in 2013-14 compared to $6,819,158$ in 2017-18.

The BDA believes that patients are being put off from seeking treatment by the government's approach to fines for 'misclaiming' free care.

More than 400,000 high needs patients a year - many on very low incomes, older people, and those with learning difficulties - have received $£ 100$ fines for ticking the wrong box on forms.

The number of fines issued went up ten-fold in the last four years, from 33,887 in 2012-13 to 365,181 in 2016-17, but 90\% of appeals were won.

NHS Business Services Authority had circulated a Don't Assume You're Entitled campaign ${ }^{2}$ to NHS practices and an official NHS Health Costs twitter feed - intended to provide advice on claiming - was routinely discouraging claims, said the BDA.

The new data also revealed that more than 4.9 million children (41.4\%) failed to see an NHS dentist in the last 12 months, while the NHS has spent $£ 165$ million on child tooth extractions in hospitals since 2012.

The Government spend per head on NHS dentistry had fallen $£ 4.95$, from $£ 40.95$ to $£ 36$, in the last five years, said the union, while patient charges had increased by more than $23 \%$.

BDA Chair of General Dental Practice Henrik Overgaard-Nielsen said: 'This huge fall in NHS attendance amongst patients exempt from NHS charges is the logical outcome of failed government policy.

'Ministers have created a hostile environment for vulnerable groups and those on low incomes who have a right to free dentistry. These patients, often with complex needs, require early intervention not the ever-present threat of fines.'

1. NHS Digital. NHS Dental Statistics for England - 2017-18, Annual Report [PAS]. 30 August 2018. Available at https://digital.nhs.uk/data-and-information/publications/statistical/ nhs-dental-statistics/2017-18-annual-report (accessed on 5 September 2018).

2. NHS Business Services Authority. Don't Assume You're Entitled poster. 2018. Available at https://www.nhsbsa.nhs.uk/sites/default/files/2018-03/Free\%20dental\%20poster\%20 2018\%20\%28V1\%29.pdf (accessed on 5 September 2018). 